\title{
Periaqueductal Gray Neuronal Activities Underlie Different Aspects of Defensive Behaviors
}

\author{
() Hanfei Deng, ${ }^{1,2 *}$ Xiong Xiao, ${ }^{1,2 *}$ and Zuoren Wang ${ }^{1}$ \\ ${ }^{1}$ Institute of Neuroscience, Chinese Academy of Sciences Center for Excellence in Brain Science and Intelligence Technology, State Key Laboratory of \\ Neuroscience, Shanghai Institutes for Biological Sciences, Chinese Academy of Sciences, Shanghai 200031, China, and ${ }^{2}$ Graduate School of University of \\ Chinese Academy of Sciences, Shanghai 200031, China
}

Defense is a basic survival mechanism when animals face danger. Previous studies have suggested that the midbrain periaqueductal gray (PAG) is essential for the generation of defensive reactions. Here we showed that optogenetic activation of neurons in the PAG in mice was sufficient to induce a series of defensive responses (including running, freezing, and avoidance). However, the endogenous neural dynamics of the PAG underlying defensive behaviors still remain elusive. Using chronic extracellular recording, we recorded the spiking activities of PAG neurons in freely behaving mice exposed to natural threats (rats). We observed that there exist distinct neuronal subsets within the PAG participating in respective detection (risk assessment) and response (flight) aspects of defensive behaviors. Our results demonstrate the important role of PAG neuronal activities in the control of different aspects of defensive behaviors, and provide novel insights for investigating defense from an electrophysiological perspective.

Key words: defensive behavior; electrophysiology; innate behavior; optogenetics; periaqueductal gray

\section{Significance Statement}

Defense is crucial for animals' survival in nature. Here, using optogenetic stimulation and in vivo recording in behaving mice reacting to threats, we explored the role of the midbrain periaqueductal gray (PAG) in defense. We show that optogenetic activation of PAG neurons is sufficient to elicit different aspects of defensive responses. Consistently, the present study provides in vivo evidence demonstrating that activity of the population of dorsal PAG neurons is activated during defense. Also, different subpopulations of units recorded in the dorsal PAG participate in distinct aspects of defensive behaviors. These findings help us understand the role of the PAG in animal behavior at the single neuron level.

\section{Introduction}

To improve their chance of survival, animals facing threats exhibit defensive behaviors (e.g., flight, freezing, and risk assessment; Fanselow, 1994; Blanchard et al., 2001a; Gross and Canteras, 2012; LeDoux, 2012). Evolutionarily, defense is conserved across numerous species, including humans (Bandler and Depaulis, 1991; Blanchard et al., 2001b), and is innate even in preweanling animals (Takahashi, 1992). Brain regions involved

Received Dec. 11, 2015; revised May 6, 2016; accepted June 1, 2016.

Author contributions: H.D., X.X., and Z.W. designed research; H.D. and X.X. performed research; H.D. and X.X. analyzed data; H.D., X.X., and Z.W. wrote the paper.

This work was supported by the Strategic Priority Research Program of the Chinese Academy of Sciences, Grant No. XDB02040000. We thank Drs. L.N. Lin and C.Y. Li for help on electrode manufacturing and data analysis, and Dr. Z.L. Qiu for help on AAV packaging.

${ }^{*} H . D$. and X.X. contributed equally to this work.

The authors declare no competing financial interests.

Correspondence should be addressed to Zuoren Wang, Institute of Neuroscience, CAS Center for Excellence in

Brain Science, State Key Laboratory of Neuroscience, Shanghai Institutes for Biological Sciences, Chinese Academy of

Sciences, Shanghai 200031, China. E-mail: zuorenwang@ion.ac.cn.

DOI:10.1523/JNEUROSCI.4425-15.2016

Copyright $\odot 2016$ the authors $\quad 0270-6474 / 16 / 367580-09 \$ 15.00 / 0$ in controlling defensive behaviors include the amygdala, the hypothalamus, and the downstream midbrain (Fanselow, 1994; Brandão et al., 1999; Petrovich et al., 2001; Canteras, 2002; Martinez et al., 2011; Gross and Canteras, 2012; LeDoux, 2012). Among these regions, the midbrain periaqueductal gray (PAG) has been considered as an effector of defensive responses. Lesions in the dorsal PAG (dPAG) attenuate animals' defensive response (including flight, freezing, and risk assessment) to threats (Blanchard et al., 1981; Sukikara et al., 2010). In addition, c-fos immunoreactive signals in the PAG are prominently enhanced in animals displaying defensive behaviors (Canteras and Goto, 1999; Dielenberg et al., 2001). Moreover, electrical or pharmacological stimulation of the PAG evokes defensive responses in rats, cats, and mice (Hunsperger, 1956; Bandler, 1982; Brandão et al., 1982; Di Scala et al., 1984; Bittencourt et al., 2005; Miguel and Nunes-de-Souza, 2006). A recent study has reported that optogenetic activation of $\mathrm{APAG}$ neurons induced defensive behaviors in rats (Chen et al., 2015).

However, the exact role of the PAG in defensive behaviors remains to be fully understood. Here we show that optogenetic 
activation of dPAG neurons in mice evoked a pattern of responses (including running, freezing, and avoidance) resembling behaviors of animals facing natural threats. Few studies have examined the neurophysiology of the PAG during defense. In the present study, we examined the neural dynamics of the dPAG in mice exposed to rats, and found that $\mathrm{dPAG}$ neural activities encoded different aspects of defensive behaviors, including flight and risk assessment. Moreover, neurons involved in threat detection and response were largely separable within this region.

\section{Materials and Methods}

Subjects. Animal procedures were conducted in compliance with institutional guidelines and approved by the Animal Care Facilities, Institute of Neuroscience, Chinese Academy of Sciences. Adult male C57BL/6 wildtype mice and Long-Evans rats (350-500 g, predator) were used.

Viral vectors. Plasmids, purchased from Addgene, originally came from Dr. K. Deisseroth. Packaged adeno-associated virus (AAV; $\sim 2 \times$ $10^{12}$ particles $/ \mathrm{ml}$ ) were produced by Neuron Biotech.

Surgery. Anesthetized mice (100 mg/kg sodium pentobarbital, i.p.) were injected with $0.5 \mu \mathrm{l}$ AAV8-CaMKII $\alpha$-ChR2-mCherry (ChR2 group) or AAV8-EF1 $\alpha$-DIO-ChR2-mCherry (control group) unilaterally into the $\mathrm{dPAG}(-4.40 \mathrm{~mm}$ posterior to bregma, $+0.28 \mathrm{~mm}$ lateral to midline, and $-2.45 \mathrm{~mm}$ ventral to the skull surface) at a rate of $30 \mathrm{nl} / \mathrm{min}$ using a Nanoliter injector and a SYS-Micro4 controller (World Precision Instruments). An optical fiber ( $200 \mu \mathrm{m}$ diameter, 0.37 numerical aperture) held in a $2.5 \mathrm{~mm}$ ferrule was implanted $0.5 \mathrm{~mm}$ above the injection site. For extracellular recording, mice were implanted with custom-made movable electrodes $(-4.40 \mathrm{~mm}$ posterior to bregma, $+1.32 \mathrm{~mm}$ lateral to midline, and $-2.35 \mathrm{~mm}$ ventral to the skull surface, at a $30^{\circ}$ angle to the vertical). The procedures of assembling the electrodes were as follows. A bundle of eight tetrodes (made from polyimide-coated $12.5 \mu \mathrm{m}$ nichrome wire) was affixed to a movable screw nut assembled in a microdrive chamber (Liu et al., 2014). Then, the electrodes were soldered to a 36-pin connector (Omnetics Connector) attached onto the microdrive chamber. Two additional wires were soldered to the corresponding pins of the connector, serving as the ground and reference wires. Before implantation, electrodes were gold-plated to reduce impedance to $\sim 300-$ $400 \mathrm{k} \Omega$ at $1 \mathrm{kHz}$ (IMP-2, Bak Electronics). For the construction of an optrode, an optical fiber ( $200 \mu \mathrm{m}$ in diameter, 0.37 numerical aperture) held in a $2.5 \mathrm{~mm}$ ferrule was affixed to the above electrode assembly. After surgery, mice were injected with ketoprofen $(2 \mathrm{mg} / \mathrm{kg}$ body weight $)$ intraperitoneally for postoperative analgesia.

Behavioral assays. Mice were coupled to a $473 \mathrm{~nm}$ laser (Shanghai Laser \& Optics Century) in a chamber $(20 \times 50 \times 30 \mathrm{~cm})$, and received photostimulation ( $1 \mathrm{~s}$ duration) in the $\mathrm{dPAG}$ with varying intensities or frequencies controlled by an Anilab instrument (Anilab Software \& Instruments). Each stimulation condition was repeated five times and interleaved by a $1 \mathrm{~min}$ intertrial interval (ITI). Laser pulse width was $15 \mathrm{~ms}$ in all optogenetic experiments unless otherwise noted.

During the real-time place-aversion test, a box $(13.5 \times 34.5 \times 30 \mathrm{~cm})$ was divided into two chambers of equal size via a barrier $(1 \mathrm{~cm}$ height $)$. After $10 \mathrm{~min}$ habituation, mice were stimulated in the dPAG $(5 \mathrm{~mW}, 20$ $\mathrm{Hz}$ ) only when they were within the designated stimulation chamber. For conditioned place-aversion assay, we modified experimental procedures from Stamatakis and Stuber (2012). Day 1 consisted of a pretest session performed in an apparatus containing two contextually distinct chambers: a black chamber $(15 \times 19 \times 30 \mathrm{~cm})$ with a stainless-steel bar floor, and a white chamber $(15 \times 19 \times 30 \mathrm{~cm})$ with evenly spaced holes (each $7 \mathrm{~mm}$ in diameter) on the floor. On days $2-4$, mice were separately placed into the initially preferred chamber to receive photostimulation into the dPAG $(5 \mathrm{~mW}, 20 \mathrm{~Hz}, 10 \mathrm{~s}$ on and $10 \mathrm{~s} \mathrm{off})$, and the other chamber without stimulation (counterbalanced, $25 \mathrm{~min}$ each). On day 5, mice were given free access to all chambers without photostimulation.

In the fear-conditioning experiment, mice underwent five pairings of a tone $(20 \mathrm{~s}, 2 \mathrm{kHz}, 75 \mathrm{~dB})$ with laser pulses $(2 \mathrm{~s}, 20 \mathrm{~Hz}, 5 \mathrm{~mW})$ delivered into the dPAG in a conditioning cage $(18 \times 22 \times 27 \mathrm{~cm})$ located in an illuminated room. The floor of the conditioning cage consisted of stainless-steel bars. After $24 \mathrm{~h}$, mice were subjected to a fear-memory recall test in a testing cage $(18 \times 22 \times 17 \mathrm{~cm})$ with holes in the side walls located in another room in darkness. A piece of Plexiglas was placed on the floor of the testing cage. Freezing was scored using the Anilab software.

In the predator-exposure test, a large compartment $(30 \times 43 \times 20 \mathrm{~cm})$ and a smaller $(30 \times 15 \times 20 \mathrm{~cm})$ compartment were separated by wire mesh. Mice were placed into the large compartment after the stimulus (toy or rat) was put into the smaller one. Mice were tested in habituation sessions (no objects or animals presented in the smaller compartment), toy sessions (a toy rat presented), and anesthetized-rat sessions (a rat anesthetized by $80 \mathrm{mg} / \mathrm{kg}$ sodium pentobarbital presented) for 3 consecutive days. In the following days, each mouse was tested in 5-7 awake-rat sessions. Each session lasted $30 \mathrm{~min}$. Stretch-attend posture was identified as a posture with an extended body length directed toward the smaller compartment (Blanchard et al., 1990, 2011; Kemble and Bolwahnn, 1997; Papes et al., 2010).

Electrophysiological recording. Neural signals were acquired (digitized at $40 \mathrm{kHz})$ and bandpass-filtered $(250-8000 \mathrm{~Hz})$ using a commercial system (Plexon). Videos (30 frames/s) were synchronized with neural signals by sending transistor-transistor logic signals from Anilab instrument to the Plexon device. Unit isolation was performed by MClust 3.5 software (A. D. Redish et al.; available at http://redishlab.neuroscience. umn.edu/). Units were isolated off-line by manually clustering spike waveform features (peak amplitude, energy, and principal components) derived from the sampled waveforms. Cluster quality was assessed by isolation distance and L ratio (Schmitzer-Torbert et al., 2005). Single units were identified based on three criteria: (1) a clear refractory period of $\geq 1 \mathrm{~ms}$; (2) isolation distance $>15$ and $\mathrm{L}$ ratio $<0.2$; (3) stable waveforms during recording.

Peri-event time histograms. Neural data were analyzed using customwritten Matlab (Mathworks) scripts. A mean spike density function was constructed for each neuron by applying a Gaussian kernel ( $\sigma=10 \mathrm{~ms})$ to each spike. All of the peri-event time histograms (PETHs) were calculated in $10 \mathrm{~ms}$ time bins. For the mean PETH, the firing rate for each unit was averaged across trials. Cells that showed a significantly increased firing rate during risk assessment and flight (compared with the firing rates at $2 \mathrm{~s}$ time window randomly chosen for 20 replicates during whole recording session; Wilcoxon rank-sum test, $p<0.001$ ) were defined as "assessment" and "flight" cells, respectively.

Histology. Coronal brain sections $(60 \mu \mathrm{m})$ were collected and stained with DAPI or fluorescent Nissl (NeuroTrace 500/525, Invitrogen) using standard procedures. For immunostaining of CaMKII $\alpha$, collected $30 \mu \mathrm{m}$ brain sections were stained with mouse anti-CaMKII $\alpha$ antibody (1:50; sc-13141, Santa Cruz Biotechnology), and the secondary antibody was donkey anti-mouse IgG Alexa 488 (1:500; Invitrogen). Fluorescent images were acquired and processed as described by Liu et al. (2014). The viral expression areas and the positions of optical fiber and electrode tips were mapped to a standard mouse coronal atlas (Paxinos and Franklin, 2001). Mice implanted with electrodes received electrolytic lesions before perfusion. Current ( $30 \mu \mathrm{A}, 10 \mathrm{~s})$ was delivered to each tetrode through a stimulus isolator (ISO-Flex, AMPI) controlled by a pulse generator (Master-8, AMPI).

Statistics. All statistical tests were performed using Prism 6 (GraphPad) and Matlab. All data are expressed as mean \pm SEM unless otherwise noted. Group differences were determined using Student's $t$ test, oneway ANOVA with Tukey's post hoc tests, or two-way ANOVA with Bonferroni's post hoc tests. We applied Wilcoxon rank-sum or signed-rank test to determine the significance of the changes in firing activities.

\section{Results}

Optogenetic activation of dPAG neurons induces

\section{defensive behaviors}

We first used optogenetics to confirm the role of dPAG in defense. We targeted dPAG CaMKII $\alpha^{+}$neurons in wild-type mice by injecting AAV carrying channelrhodopsin-2 (ChR2) under a CaMKII $\alpha$ promoter (Fig. $1 A, B$ ), and implanted mice with optical fibers (Fig. 1C). We validated that $\sim 66 \%(66.42 \pm 3.51 \%$; mean \pm SD) of CaMKII $\alpha$-expressing neurons were $\mathrm{mCherry}^{+}$in 
A
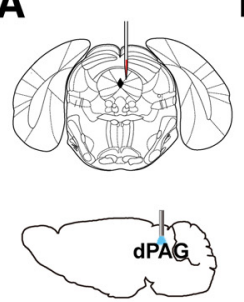

B

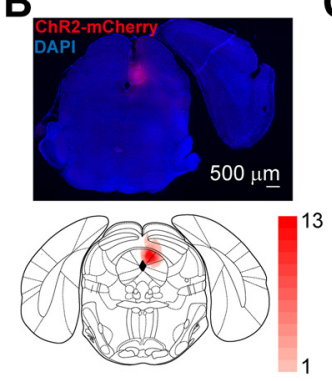

F

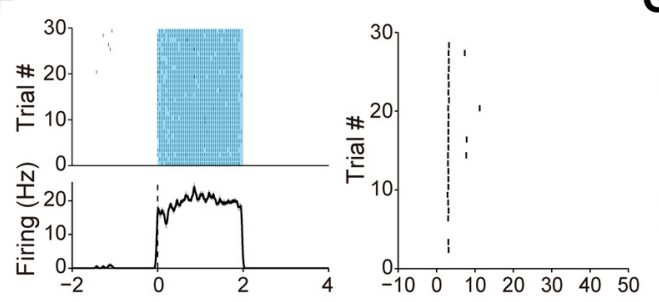

Time from laser onset (s) Time from laser onset (ms)
C

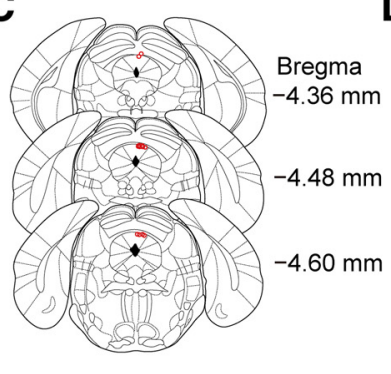

G

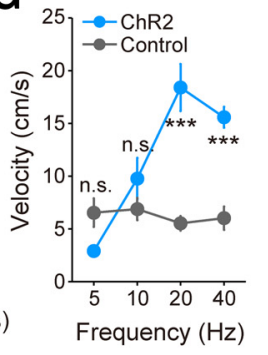

D
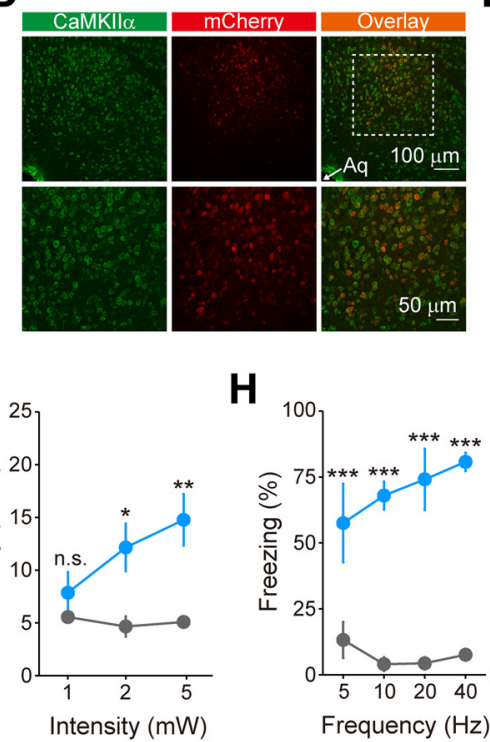

E

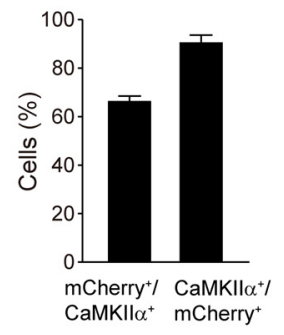

I

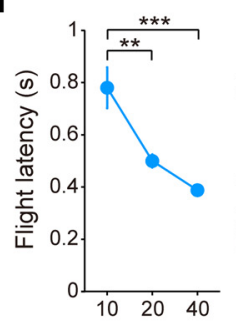

Frequency $(\mathrm{Hz})$

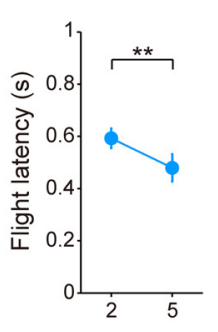

Intensity $(\mathrm{mW})$
J

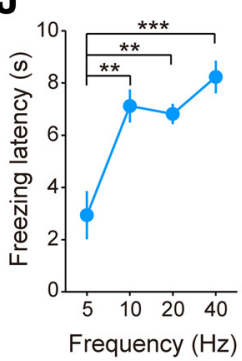

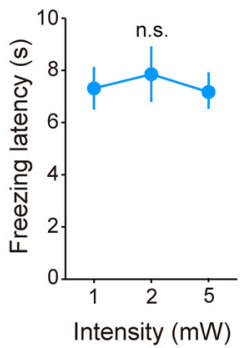

H

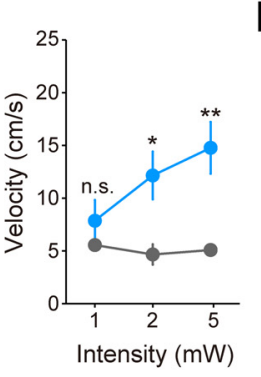

K

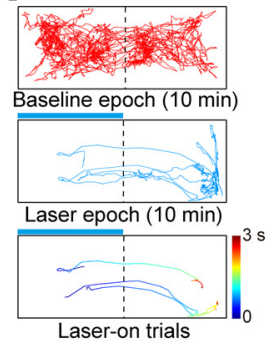

L

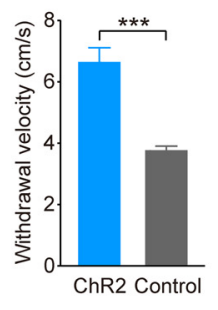

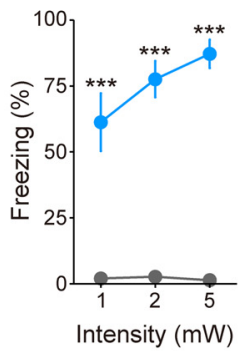

M

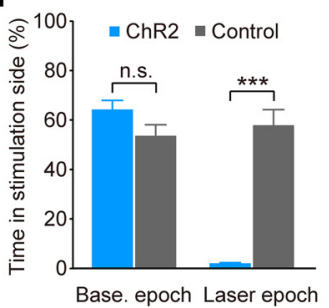

N

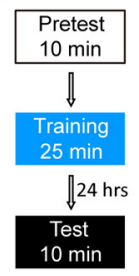

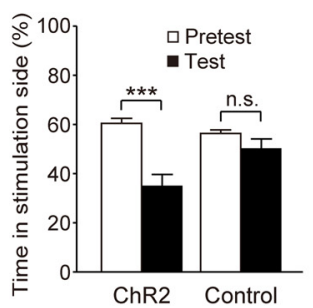

0

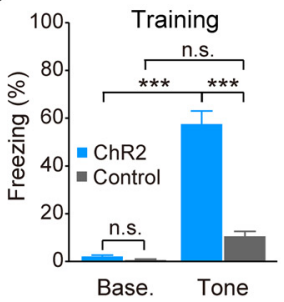

Figure 1. Optogenetic activation of dPAG neurons evokes defensive behaviors. $\boldsymbol{A}$, Schematic showing virus injection (top) and implantation of optical fiber (bottom) into the dPAG. $\boldsymbol{B}$, Top, Visualization of ChR2-mCherry expression in the dPAG (DAPI, blue; ChR2-mCherry, red). Bottom, Overlay of virus expression ( $n=13$ mice). Color bar, the number of mice with virus expressed in that area. $\boldsymbol{C}$, Placement of optical fiber tips (red circles; $n=13$ mice). $\boldsymbol{D}$, Top, Representative immunostaining images showing virally induced mCherry expression under the CaMKIll $\alpha$ promoter and endogenous CaMKII $\alpha$ expression immunolabeled with anti-CaMKII $\alpha$ antibody. Bottom, Higher-magnification images of the boxed area in the top panels. Arrowhead indicates aqueduct (Aq). $\boldsymbol{E}$, Percentage of overlap between dPAG CaMKIll $\alpha^{+}$and $\mathrm{mCherry}{ }^{+}$cells $(n=3$ mice, 3 sections for each mice). $\boldsymbol{F}$, Activity of an example unit in response to laser stimulation (blue shading; $5 \mathrm{~mW}, 20$ $\mathrm{Hz}, 1 \mathrm{~ms}$ pulse). Left, Top, Spike raster, with each row corresponding to a single trial and each tick to a single spike. Left, Bottom, Peri-stimulus time histogram calculated by averaging firing rates across trials. Gray shading, SEM. Right, Spike raster showing latency following first laser pulse stimulation ( $3.07 \pm 0.08 \mathrm{~ms}$; mean \pm SD). $\mathbf{G}, \boldsymbol{H}$, Velocity during photostimulation (G) and freezing percentage during ITI $(\boldsymbol{H})$ at different pulse frequencies (power, $5 \mathrm{~mW}$ ) and laser intensities (frequency, $20 \mathrm{~Hz}$ ) in the ChR2 and control groups $(n=5$ per group). Two-way ANOVA with Bonferroni's post hoc analysis. $I, J$, Latencies from laser stimulation to flight $(I)$ and freezing $(J)$ onset at different pulse frequencies (power, $5 \mathrm{~mW})$ and laser intensities (frequency, $20 \mathrm{~Hz})$ in the $C \mathrm{Ch} 2 \mathrm{group}(n=$ 5). $I$, Left, One-way ANOVA, $F_{(2,8)}=18.89, p=0.0009$, Tukey's post hoc. $I$, Right, Paired $t$ test, $t_{(4)}=4.659, p=0.0096$. J, Left, One-way ANOVA, $F_{(3,12)}=12.06, p=0.0006$, Tukey's post hoc. $\boldsymbol{J}$, Right, One-way ANOVA, $F_{(2,8)}=0.3364, p=0.7239$, Tukey's post hoc. $\boldsymbol{K}$, Locomotion tracks of a representative ChR2-expressing mouse during real-time place-aversion test. Blue bar, Laser delivery; color bar, time; time 0 , laser onset. $L$, Withdrawal velocity (left, $t$ test, $t_{(8)}=5.9824, p<0.001$ ) and withdrawal latency (right, $t$ test, $t_{(8)}=-5.8712, p<0.001$ ) in response to laser illumination in the real-time place-aversion test in the ChR2 and control groups $(n=5$ per group). $M$, Percentage of time spent in stimulation chamber during baseline and laser epochs in the ChR2 and control groups (group $\times$ epoch interaction, $F_{(1,8)}=66.74, p<0.001$; two-way ANOVA, Bonferroni's post hoc.; $n=5$ per group). $\boldsymbol{N}$, Schematic of conditioned place-aversion test (left). Time that ChR2 $(n=8)$ and control $(n=7)$ groups spent in the stimulation-paired chamber on the pretest and test days (right; group $\times$ day interaction, $F_{(1,13)}=10.24, p=$ 0.007; two-way ANOVA, Bonferroni post hoc). $\mathbf{0}$, Freezing percentage during the baseline and tone presentation periods on the training $\left(F_{(1,18)}=55.35, p<0.0001\right)$ and test $\left(F_{(1,18)}=\right.$ $21.31, p=0.0002$ ) days in the ChR2 and control groups (two-way ANOVA, Bonferroni's post hoc.; $n=10$ per group). On both the training and test days, the ChR2 group showed significantly higher level of freezing during tone presentation compared with the baseline period ( $p<0.0001$ for training day; $p<0.0001$ for test day; two-way ANOVA, Bonferroni's posthoc.) and the control group ( $p<0.0001$ for training day; $p<0.0001$ for test day; two-way ANOVA, Bonferroni's post hoc.). Error bars, SEM; $n . S .$, nonsignificant, $p>0.05 ;{ }^{*} p<0.05$; ${ }^{* *} p<0.01$; ${ }^{* *} p<0.001$. 
dPAG, and $\sim 90 \%(90.64 \pm 5.13 \%$; mean \pm SD) of mCherryexpressing neurons were $\mathrm{CaMKII} \alpha^{+}$(Fig. 1D,E). Extracellular recording using optrodes in ChR2-expressing mice confirmed the effectiveness of optogenetic activation (Fig. $1 F$ ). To investigate behavioral effects of optogenetic activation of dPAG neurons, we tested mice systematically using lasers with varying intensities and frequencies. Photostimulation at higher-frequency or higher-intensity values induced running reliably in the ChR2 group but not in the control group (wild-type mice injected with AAV8-EF1 $\alpha$-DIO-ChR2-mCherry, without expression of ChR2 and mCherry), as indicated by significant increase in animals' velocity during photostimulation (Fig. $1 G$ ). We observed that no risk-assessment behavior occurred during photostimulation. Moreover, ChR2-expressing mice exhibited poststimulation freezing during the ITI, and the freezing levels showed a progressively increasing trend along with the increase of laserstimulation strength (Fig. $1 H$ ). We also observed shorter latency for ChR2 mice to initiate flight upon laser stimulations with higher-frequency or higher-intensity values (Fig. 1I), while there was no such tendency for the latency from stimulation to freezing onset (Fig. 1J).

Next, we asked whether activation of dPAG neurons could produce avoidance in a real-time place-aversion tests. Laser illumination was presented only when animals were within a designated stimulation chamber during laser epoch. Upon photostimulation, ChR2-expressing mice withdrew rapidly from the stimulation chamber (Fig. $1 K, L$ ). Compared with controls, ChR2 mice spent significantly less time in the stimulation chamber during the laser epoch, while no significant differences were observed during the baseline epoch (Fig. 1M). Further experiments using contextually distinct chambers showed that ChR2-expressing mice displayed significant conditioned place avoidance for the stimulation-paired chamber on the test day (Fig. $1 N$ ). Also, when photostimulation of dPAG was paired with conditional tone stimulus in a chamber allowing no avoidance, ChR2-expressing mice displayed freezing behavior during tone presentation both in conditioning and test phases (Fig. 1O), confirming that activation of $\mathrm{APAG}$ neurons serves as an unconditioned stimulus. Together, optogenetic activation of dPAG neurons promotes running, freezing, and acute and conditioned avoidance, mimicking defensive reactions of animals facing danger.

\section{Rats induce defensive behaviors in mice}

To further address what endogenous neural activities of the dPAG underlie defense, we induced defensive behaviors in mice in a more natural context, namely by exposing them to rats, which have been reported as predators of mice (Horovitz et al., 1965; O’Boyle, 1974; Malick, 1975; Rylov, 1985; de Catanzaro, 1988; Blanchard et al., 2001a). We used an apparatus divided by wire mesh into two compartments of different sizes (Fig. 2A). Mice were allowed to move freely only in the larger compartment, while an awake rat was confined to the smaller one (rat session). As controls, we introduced a habituation session with an empty smaller compartment, and a toy session with a toy rat placed in the smaller compartment. To examine whether exposure to rats induced defensive behaviors in mice, we analyzed three different kinds of behavior: avoidance behavior, flight behavior, and risk-assessment behavior, which could be identified by a stretch-attend response with a flat-back elongated posture (Blanchard et al., 1990, 2011; Kemble and Bolwahnn, 1997; Papes et al., 2010). During habituation or toy sessions, mice actively explored the larger compartment as observed by upward rearing and even hanging onto the wire mesh. By contrast, mice displayed marked avoidance of rats (Fig. $2 B-D$ ). Moreover, mice showed greater numbers of flight and risk-assessment responses during the rat sessions than during habituation or toy sessions, as indicated by a significantly higher velocity of running away from the wire mesh and an increased number of episodes showing stretchattend postures (Fig. 2E,F). Overall, these results validate that mice exhibit innate defensive reactions (including avoidance, flight, and risk assessment) upon exposure to rats.

\section{Flight cells in dPAG}

Since optogenetic activation of dPAG neurons induced flight, we reasoned that neurons related to flight might exist in this brain region. We observed that mice detecting a rat would suddenly draw back in an apparent attempt to initiate escape as they stayed around the wire mesh (Fig. 2G). We defined a "flight episode" as starting with the moment of retraction and ending with the moment when mice arrived at the opposite side of the chamber. In total, we collected by extracellular recording 165 single units in the dPAG from five mice exposed to rats (Fig. $3 A, B$ ). Figure $3 C$ shows units exhibiting significantly increased firing rates during flight ("flight" cells). Next, to examine the neural dynamics of flight cells during flight, we plotted their firing rates versus the mouse's distance from the wire mesh (Fig. 3D). Flight cells exhibited prominent firing initially, but the firing declined gradually as mice fled farther from the rat. In contrast, flight cells were barely responsive when mice moved toward the wire mesh. Then, we evaluated a potential correlation between movement velocity and firing activity for each flight cell. We found that the firing rates of flight cells were not correlated with the instantaneous velocity during the flight period (Fig. $3 E$, left), whereas the correlation coefficients between mean firing activity in any given flight episode and the corresponding maximum flight velocity were positively skewed at the population level (Fig. 3E, right). Further analysis showed that the firing peak of flight cells occurred earlier than the velocity peak (maximum flight velocity; Fig. $3 F$ ).

\section{Assessment cells in the dPAG}

Risk-assessment behavior is crucial for animals to detect and analyze threats in the surrounding environment (Blanchard et al., 2011). We observed that flight behavior was often preceded by a period when mice showed risk-assessment behavior: investigating around the wire mesh for a while with a stretch-attend posture (Fig. 2G). We found that some units recorded in the dPAG showed higher firing activities during this surveillance period ("assessment" cells; Fig. 3G). Next, we tested whether these units' firing activities were correlated with distance from the wire mesh. We plotted instantaneous firing rates of assessment cells against each mouse's distance from the wire mesh, and found that neuronal spikes occurred more frequently when animals were near the wire mesh (Fig. $3 H$ ). To further determine whether the neural activities were related specifically to risk-assessment behavior or generally to behavioral inhibition, we examined the activities of assessment cells during freezing. We found that assessment cells were not responsive during freezing episodes (Fig. $3 I, J$ ).

\section{Different aspects of defensive behaviors are encoded by distinct neuronal subsets}

Risk assessment and flight constitute consecutive defensive phases in our paradigm. We then asked whether the dPAG units encoding these two phases overlapped or were segregated. We observed that units responsive during both phases were rare (2\%), whereas flight-specific units comprised $\sim 22 \%$ of total 
A Habituation session

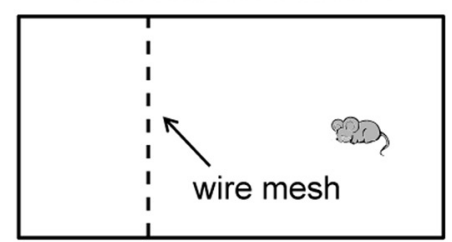

B

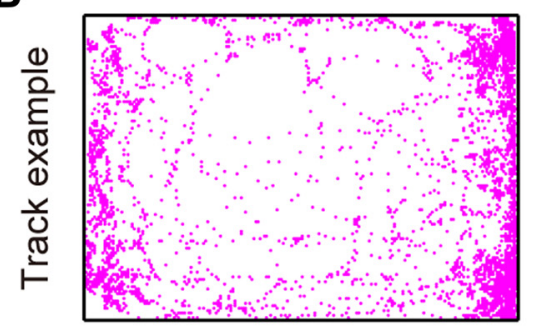

C

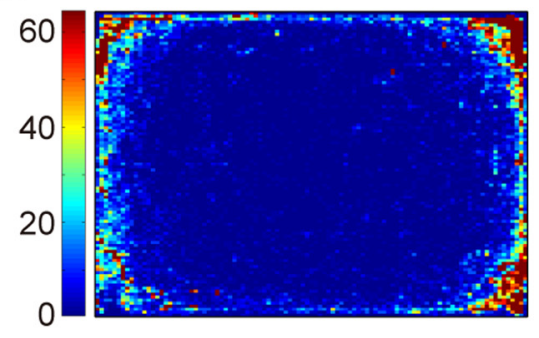

D

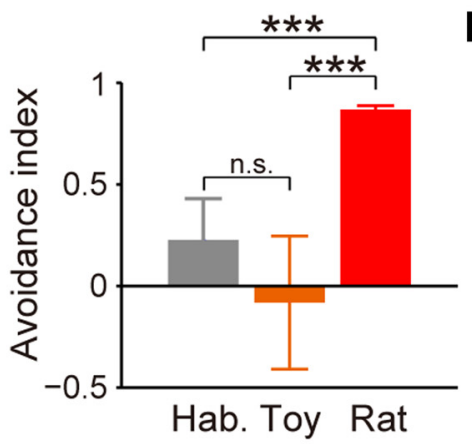

G

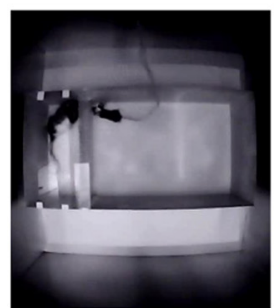

Risk assessment

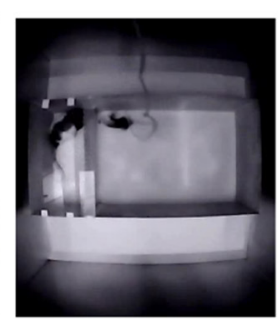

Retraction
E
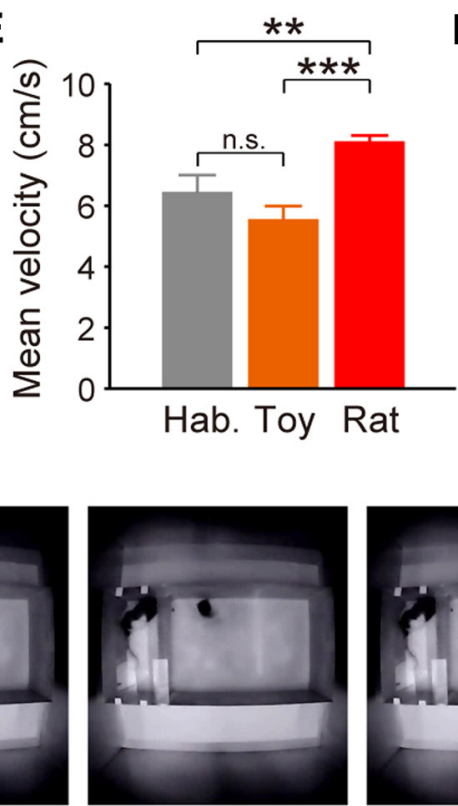

Turning around
Toy session
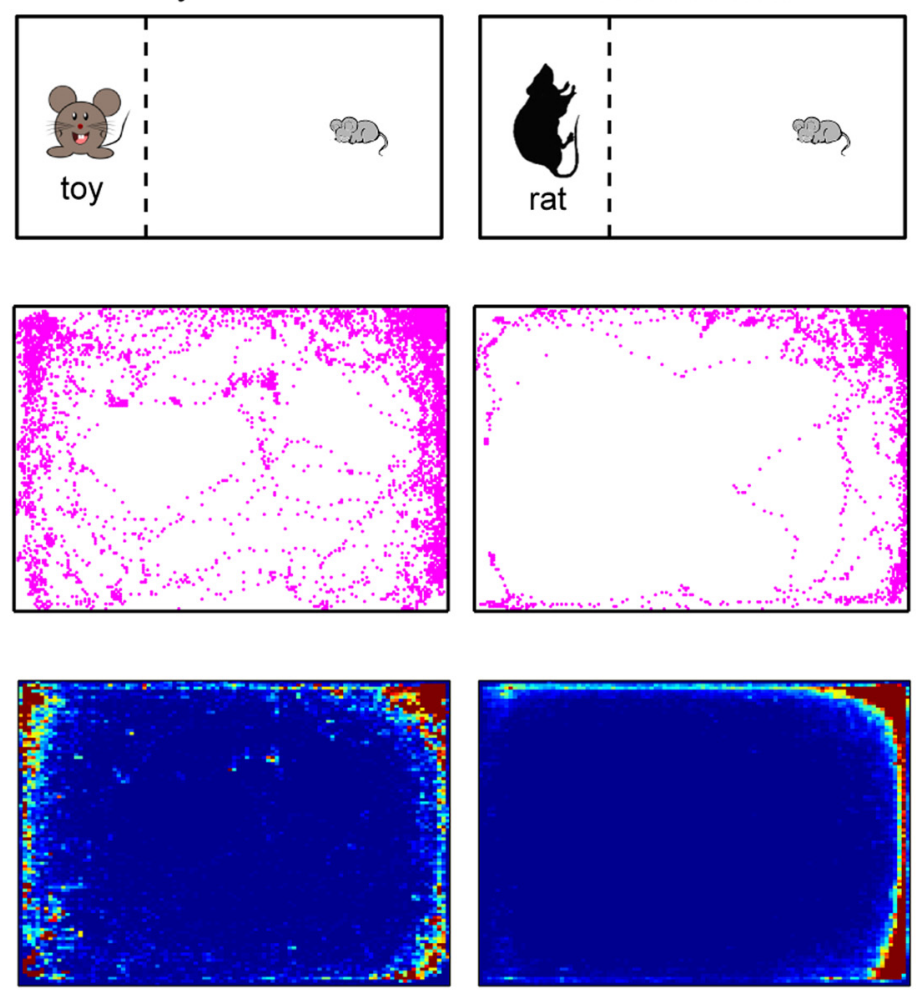

$\mathbf{F}$

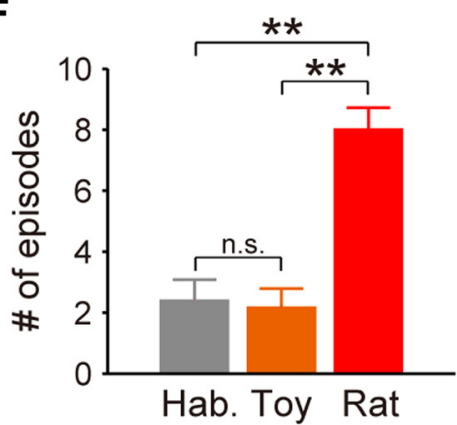

Figure 2. Rat exposure induces defensive behaviors in mice. $\boldsymbol{A}$, Schematic showing induction of defensive behaviors in mice. Mice were tested in habituation, toy, and rat sessions. $\boldsymbol{B}$, Locomotion tracks of a representative mouse during habituation (left), toy (middle), and rat (right) sessions. $C$, Heatmaps illustrating density of spatial location across all experimental mice ( $n=7$ ) during habituation (left), toy (middle), and rat (right) sessions. Color bar represents time spent in a specific area normalized by the average time if the mouse had no spatial preference. $D$, Avoidance index (as calculated by the percentage of time spent in the half zone far from the wire mesh minus time spent in the other half near the wire mesh) during habituation, toy, and rat sessions $\left(F_{(2,52)}=32.5\right.$, $p<0.001)$. $\boldsymbol{E}$, Quantification of flight behavior (as measured by average velocity of mice moving away from the wire mesh) during habituation, toy, and rat sessions $\left(F_{(2,52)}=12.5, p<0.001\right) . \boldsymbol{F}$, Quantification of risk-assessment behavior (as scored by the number of stretch-attend episodes) during habituation, toy, and rat sessions $\left(F_{(2,52)}=9.4, p<0.001\right)$. $G$, Video frames showing a representative mouse's defensive behavior during exposure to awake rat. Group data were pooled from seven mice. Error bars, SEM; one-way ANOVA, Tukey's post hoc; $n . S .$, nonsignificant, $p>0.05$; ${ }^{* *} p<0.01 ;{ }^{* * *} p<0.001$. 
A

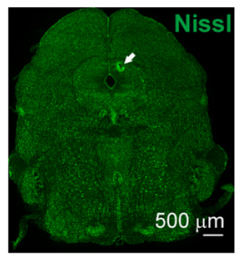

C

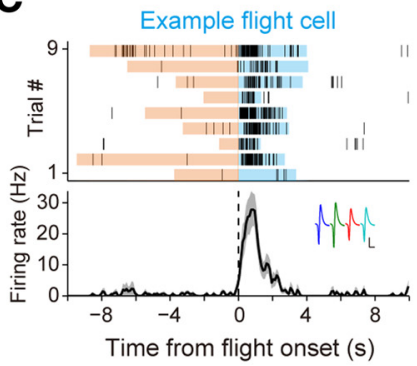

E

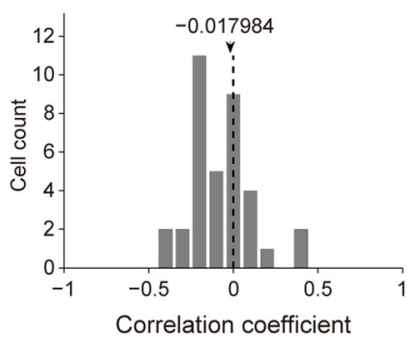

G

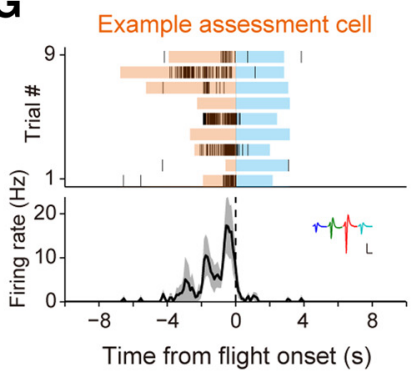

I

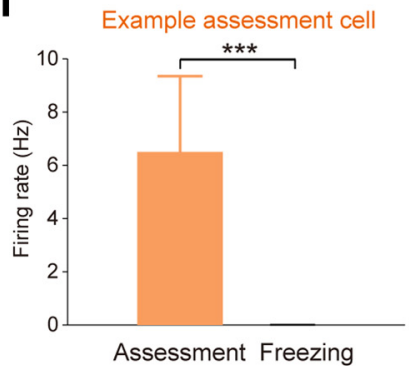

B

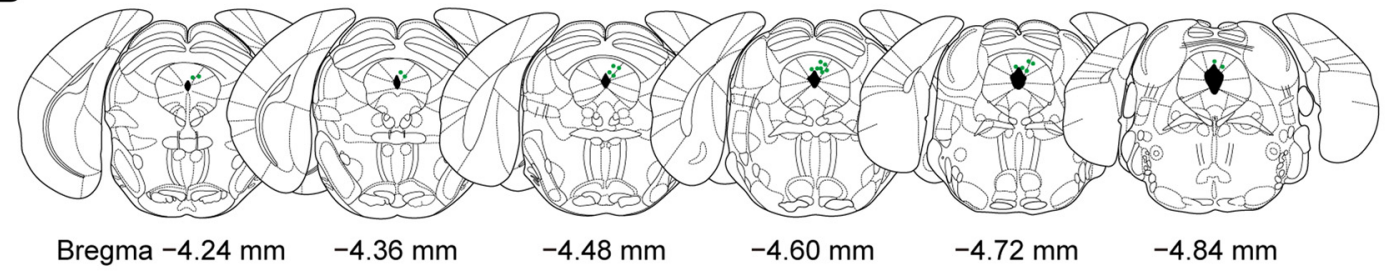

D
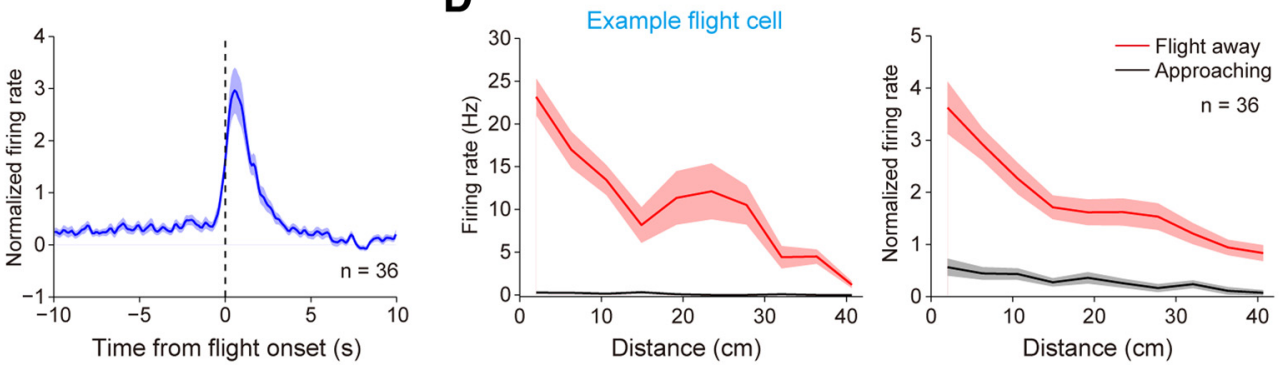

F
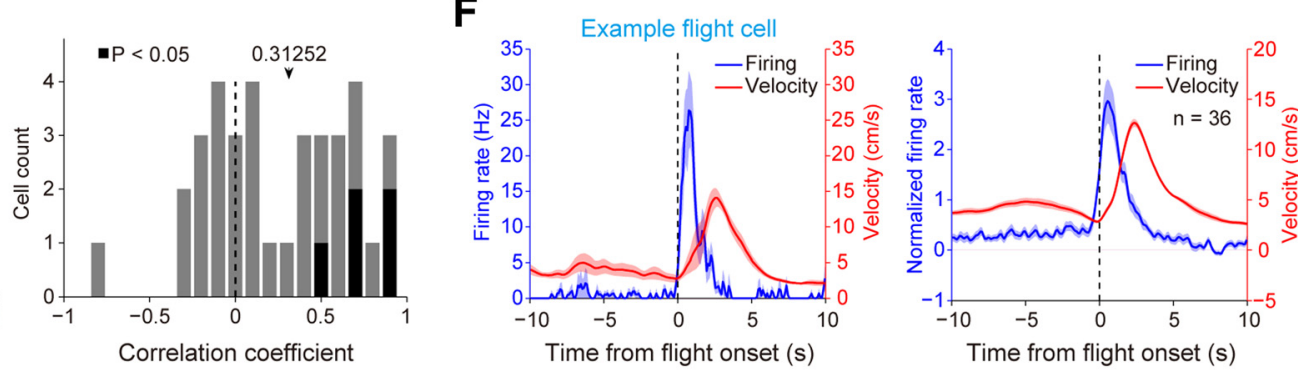

H
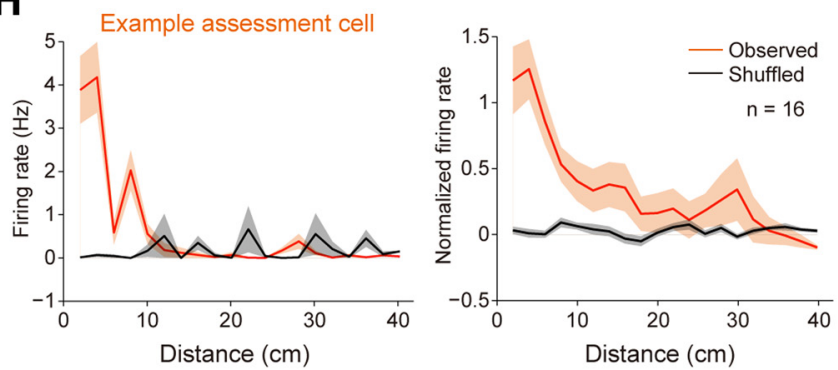

J
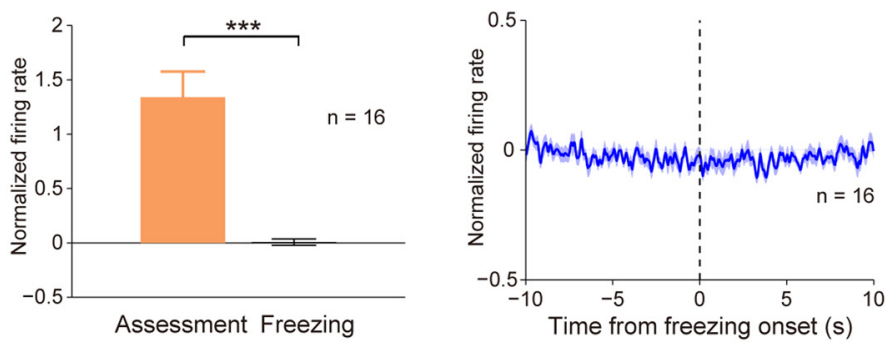

Figure 3. Activities of units recorded in the dPAG during defense. $\boldsymbol{A}$, Fluorescent Nissl staining showing an electrolytic lesion site (white arrow). B, Summary of electrode recording sites (green dots). C, Left, Example of a flight cell. Trials were aligned to flight onset. Blue shading, Flight episode; orange, risk-assessment episode. Inset, Spike waveforms. scale bars: $100 \mu$ V, $500 \mu$ s. Right, Normalized average PETH across all 36 flight cells. D, Firing rate of an example flight cell (left; same cell in $C$, left) and normalized average firing rates of all flight cells (right) plotted as a function of distance to the wire mesh. Red, Running away from the wire mesh. Black, Running toward the wire mesh. $\boldsymbol{E}$, Left, Distribution of correlation coefficients (Pearson's $r$ ) between instantaneous velocity and firing rates of flight cells during flight period. Right, Distribution of correlation coefficients (Pearson's $r$ ) between maximum flight velocity and mean firing rates of flight cells during each flight episode. Black bars indicate significance (Pearson's $p<0.05$ ); gray bars indicate no significance. $\boldsymbol{F}$, Left, Firing activity of an example flight cell (same cell in $\boldsymbol{C}$, left) and the mouse's instantaneous velocity during flight. Right, Normalized average firing activities of flight cells and the corresponding instantaneous velocity during flight. $\mathbf{G}$, Left, Example of a risk-assessment cell. Inset, Spike waveforms. Scale bars: $100 \mu \mathrm{V}, 500 \mu$ s. Right, Normalized average PETH across all 16 assessment cells. $\boldsymbol{H}$, Firing rate of an example assessment cell (left; same cell in $\boldsymbol{G}$, left) and normalized average firing rates of all assessment cells (right) plotted as a function of distance to the wire mesh. Orange, Observed data. Black, Shuffled data. $I$, Average firing rate of an example assessment cell (left; Wilcoxon rank-sum test, ${ }^{* * *} p<0.001$; same cell in $\mathbf{G}$, left) and normalized average firing rates of all assessment cells (right; Wilcoxon signed-rank test, ${ }^{* * *} p<0.001$ ) during risk assessment and freezing episodes. Error bars, SEM. J, Normalized average PETH aligned to freezing onset across all 16 assessment cells. 
A
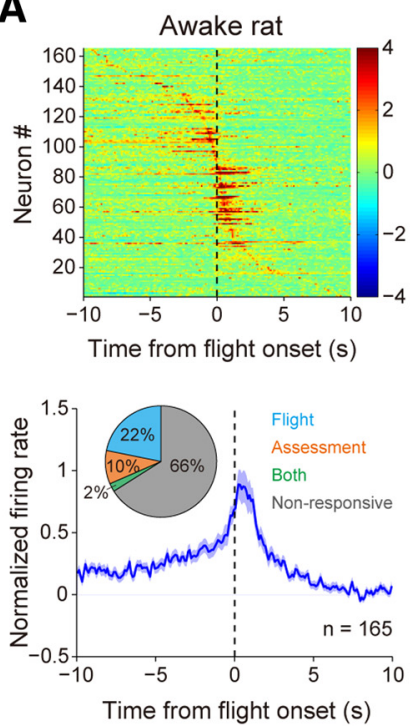

B
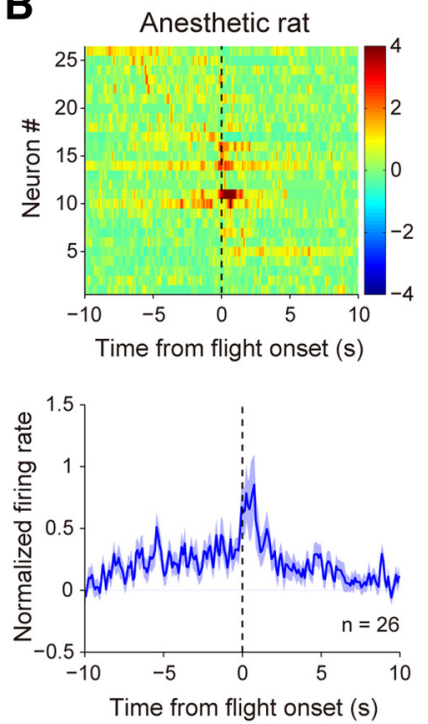

C
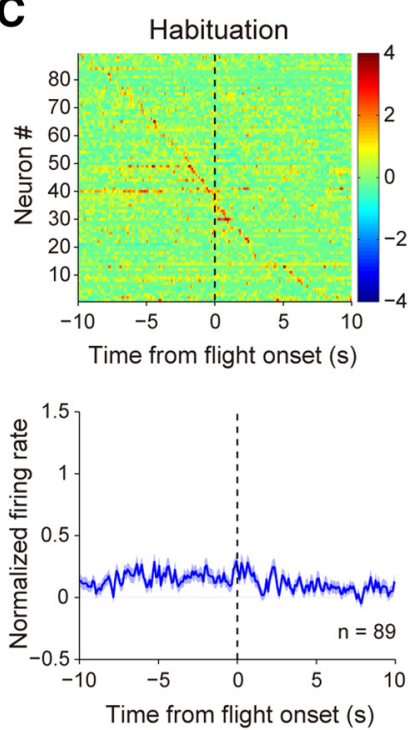

D
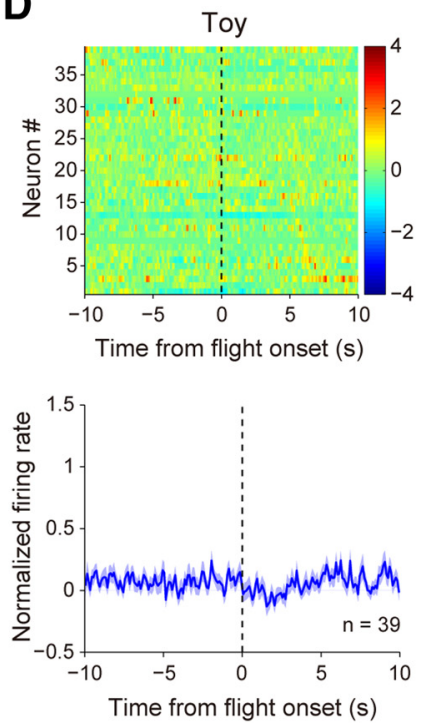

Figure 4. Activities of units recorded in the dPAG during awake-rat, anesthetized-rat, habituation, and toy sessions. $A$, Top, Activities of dPAG units recorded during awake-rat sessions, with each row corresponding to one unit and color scale indicating normalized firing activity. Units were sorted by time of peak firing rate for each unit. Bottom, Normalized average PETH of dPAG units. Inset, Pie plot showing population distribution (flight-specific units, 22\%; risk assessment-specific units, 10\%; units exhibiting both features, 2\%). B-D, Top, Normalized activities of dPAG units recorded during anesthetized-rat $(\boldsymbol{B})$, habituation $(\boldsymbol{C})$, and toy $(\boldsymbol{D})$ sessions. Bottom, Normalized average PETH of dPAG units recorded during each session.

units and assessment-specific units comprised a smaller (10\%) proportion (Fig. $4 A$ ), suggesting that distinct subsets of dPAG cells are recruited during different processes of defense.

In sessions with awake rats, the normalized average activity of dPAG units increased gradually during risk assessment and peaked during flight (Fig. 4A). Similar to exposure to awake rats, exposure to anesthetized rats triggered defensive behaviors in mice and induced a similar firing pattern in dPAG units (Fig. 4B). To determine whether the neural responses were specifically related to defense or to an unrelated disturbance (such as novelty or a mouse's nonspecific motor activity), we examined the spiking activities of dPAG units during habituation and toy sessions. After plotting neural responses aligned by the time point when mice left the wire mesh, we did not observe firing patterns similar to those seen in sessions that included rats (Fig. 4C,D). Overall, we conclude that the dPAG exhibits specific neuronal activities during risk assessment and flight, representing two aspects of defensive reactions.

\section{Discussion}

Here, we showed that optogenetic activation of dPAG CaMKII $\alpha^{+}$ neurons induced defensive responses (including running, freezing, and avoidance). Compared with electrical and chemical stimulations, optogenetic stimulation provides cellular specificity and high temporal resolution without activating passing fibers, a drawback of electrical stimulation (Fenno et al., 2011). It has also been reported that pharmacogenetic silencing of dPAG neurons in mice decreases the duration of defensive responses following exposure to a living rat (Silva et al., 2013). Together, this and our results show that the dPAG is necessary and sufficient to induce defensive behavior. Intriguingly, it is reported that optogenetic activation of the ventromedial hypothalamus (VMH)-dorsolateral PAG pathway produces immobility, but not flight or avoidance (Wang et al., 2015). Given that the induction of flight or avoidance may require additional threat inputs that are not provided by the VMH, the behavioral effect of VMHPAG pathway activation should be further tested in the presence of a live predator or a predatory odor. It is reported that direct stimulation of the VMH induces flight behavior with (Lipp and Hunsperger, 1978) or without (Lin et al., 2011) a threat present. Also, there exists an indirect projection from the $\mathrm{VMH}$ to the PAG via the dorsal premammillary nucleus (PMd), another medial hypothalamus nucleus crucial for the expression of defensive behavior (Canteras and Swanson, 1992; Canteras et al., 1994, 1997; Blanchard et al., 2003). Thus, future work will need to examine whether activation of the VMH-PMd-PAG circuit elicits flight, and to address whether the VMH neurons that have direct and indirect inputs to PAG are segregated or overlap.

Multiple behavioral processes are orchestrated to fulfill complex behavioral patterns. At the cellular level, different aspects of a behavior could be encoded by overlapping or separate neuronal subpopulations (Falkner et al., 2014; Jennings et al., 2015). Our extracellular recording in freely behaving mice identified two largely segregated subsets of units (assessment and flight cells, respectively) that correspond to the detection of and response to a live rat. It remains to be determined whether these two aspects of defensive reactions are dissociated in other brain regions involved in defense. The dPAG neuronal activities were activated during sessions involving rat exposure, but were almost nonresponsive during habituation and toy sessions. Moreover, it has been shown that neurons in the dPAG are activated when rats express conditioned fear responses (Halladay and Blair, 2015). The observed neuronal activation during defense is consistent with the results of optogenetic activation experiments.

Our study also reveals some previously uncharacterized features of dPAG neurons. As to flight cells, their firing activities were not correlated with instantaneous movement velocity during flight, but were positively correlated with maximum flight velocity on a trial-by-trial basis. Due to the limited temporal video resolution, further studies using headstage-mounted accelerometers are needed to reveal the more precise relationship between neuronal activities and animals' movement velocity. As to assessment cells, their spiking activities were inversely correlated with the distance from a threatening stimulus. These observations provide electrophysiological evidence suggesting that $\mathrm{dPAG}$ 
is not simply a premotor area and reflects animals' underlying defensive state, in agreement with previous work (Nashold et al., 1969; Johansen et al., 2010; Kincheski et al., 2012; Kim et al., 2013; Carvalho et al., 2015). The finding of dPAG units related to risk assessment expands what was previously detected by stimulation and c-fos studies (Brandão et al., 1982; Di Scala et al., 1984; Canteras and Goto, 1999; Dielenberg et al., 2001; Bittencourt et al., 2005; Miguel and Nunes-de-Souza, 2006), and is also consistent with previous lesion studies (Sukikara et al., 2010). Activation of dPAG neurons did not induce risk-assessment behavior in the present study, and also the induction of risk-assessment behavior by dPAG stimulation is not reported by other studies (Brandão et al., 1982; Di Scala et al., 1984; Bittencourt et al., 2005; Miguel and Nunes-de-Souza, 2006). It is possible that flight cells outweighed the behavioral output of assessment cells. After all, assessment cells constitute a smaller population (10\%) than flight cells (22\%). In addition, assessment cells resemble a type of VMH neuron responsive in mice investigating male conspecific mice (Lin et al., 2011; Falkner et al., 2014). To better understand predator-fear processing at the circuit level, researchers should further examine the spiking activities in the medial hypothalamic nuclei, including those of the $\mathrm{VMH}$ and $\mathrm{PMd}$, during predator exposure, and explore the functional inputs that $\mathrm{DPAG}$ neurons receive from these nuclei.

\section{References}

Bandler R (1982) Induction of 'rage' following microinjections of glutamate into midbrain but not hypothalamus of cats. Neurosci Lett 30:183-188. CrossRef Medline

Bandler R, Depaulis A (1991) Midbrain periaqueductal gray control of defensive behavior in the cat and the rat. In: The midbrain periaqueductal gray matter (Depaulis A, Bandler R, eds), pp 175-198. New York: Springer.

Bittencourt AS, Nakamura-Palacios EM, Mauad H, Tufik S, Schenberg LC (2005) Organization of electrically and chemically evoked defensive behaviors within the deeper collicular layers as compared to the periaqueductal gray matter of the rat. Neuroscience 133:873-892. CrossRef Medline

Blanchard DC, Williams G, Lee E, Blanchard RJ (1981) Taming of wild Rattus norvegicus by lesions of the mesencephalic central gray. Physiol Psychol 9:157-163. CrossRef

Blanchard DC, Griebel G, Blanchard RJ (2001a) Mouse defensive behaviors: pharmacological and behavioral assays for anxiety and panic. Neurosci Biobehav Rev 25:205-218. CrossRef Medline

Blanchard DC, Hynd AL, Minke KA, Minemoto T, Blanchard RJ (2001b) Human defensive behaviors to threat scenarios show parallels to fear- and anxiety-related defense patterns of nonhuman mammals. Neurosci Biobehav Rev 25:761-770. CrossRef Medline

Blanchard DC, Li CI, Hubbard D, Markham CM, Yang M, Takahashi LK, Blanchard RJ (2003) Dorsal premammillary nucleus differentially modulates defensive behaviors induced by different threat stimuli in rats. Neurosci Lett 345:145-148. CrossRef Medline

Blanchard DC, Griebel G, Pobbe R, Blanchard RJ (2011) Risk assessment as an evolved threat detection and analysis process. Neurosci Biobehav Rev 35:991-998. CrossRef Medline

Blanchard RJ, Blanchard DC, Weiss SM, Meyer S (1990) The effects of ethanol and diazepam on reactions to predatory odors. Pharmacol Biochem Behav 35:775-780. CrossRef Medline

Brandão ML, de Aguiar JC, Graeff FG (1982) GABA mediation of the antiaversive action of minor tranquilizers. Pharmacol Biochem Behav 16: 397-402. CrossRef Medline

Brandão ML, Anseloni VZ, Pandóssio JE, De AraújoJE, Castilho VM (1999) Neurochemical mechanisms of the defensive behavior in the dorsal midbrain. Neurosci Biobehav Rev 23:863-875. CrossRef Medline

Canteras NS (2002) The medial hypothalamic defensive system: hodological organization and functional implications. Pharmacol Biochem Behav 71:481-491. CrossRef Medline

Canteras NS, Goto M (1999) Fos-like immunoreactivity in the periaque- ductal gray of rats exposed to a natural predator. Neuroreport 10:413418. CrossRef Medline

Canteras NS, Swanson LW (1992) The dorsal premammillary nucleus: an unusual component of the mammillary body. Proc Natl Acad Sci U S A 89:10089-10093. CrossRef Medline

Canteras NS, Simerly RB, Swanson LW (1994) Organization of projections from the ventromedial nucleus of the hypothalamus: a Phaseolus vulgaris-leucoagglutinin study in the rat. J Comp Neurol 348:41-79. CrossRef Medline

Canteras NS, Chiavegatto S, Ribeiro do Valle LE, Swanson LW (1997) Severe reduction of rat defensive behavior to a predator by discrete hypothalamic chemical lesions. Brain Res Bull 44:297-305. CrossRef Medline

Carvalho MC, Santos JM, Brandão ML (2015) Dorsal periaqueductal gray post-stimulation freezing is counteracted by neurokinin-1 receptor antagonism in the central nucleus of the amygdala in rats. Neurobiol Learn Mem 121:52-58. CrossRef Medline

Chen S, Zhou H, Guo S, Zhang J, Qu Y, Feng Z, Xu K, Zheng X (2015) Optogenetics based rat-robot control: optical stimulation encodes "stop" and "escape" commands. Ann Biomed Eng 43:1851-1864. CrossRef Medline

de Catanzaro D (1988) Effect of predator exposure upon early pregnancy in mice. Physiol Behav 43:691-696. CrossRef Medline

Dielenberg RA, Hunt GE, McGregor IS (2001) "When a rat smells a cat": the distribution of Fos immunoreactivity in rat brain following exposure to a predatory odor. Neuroscience 104:1085-1097. CrossRef Medline

Di Scala G, Schmitt P, Karli P (1984) Flight induced by infusion of bicuculline methiodide into periventricular structures. Brain Res 309:199-208. CrossRef Medline

Falkner AL, Dollar P, Perona P, Anderson DJ, Lin D (2014) Decoding ventromedial hypothalamic neural activity during male mouse aggression. J Neurosci 34:5971-5984. CrossRef Medline

Fanselow MS (1994) Neural organization of the defensive behavior system responsible for fear. Psychon Bull Rev 1:429-438. CrossRef Medline

Fenno L, Yizhar O, Deisseroth K (2011) The development and application of optogenetics. Annu Rev Neurosci 34:389-412. CrossRef Medline

Gross CT, Canteras NS (2012) The many paths to fear. Nat Rev Neurosci 13:651-658. CrossRef Medline

Halladay LR, Blair HT (2015) Distinct ensembles of medial prefrontal cortex neurons are activated by threatening stimuli that elicit excitation vs. inhibition of movement. J Neurophysiol 114:793-807. CrossRef Medline

Horovitz ZP, Ragozzino PW, Leaf RC (1965) Selective block of rat mousekilling by antidepressants. Life Sci 4:1909-1912. CrossRef Medline

Hunsperger RW (1956) Affektreaktionen auf elektrische Reizung im Hirnstamm der Katze. Helv Physiol Pharmacol Acta 14:70-92. Medline

Jennings JH, Ung RL, Resendez SL, Stamatakis AM, Taylor JG, Huang J, Veleta K, Kantak PA, Aita M, Shilling-Scrivo K, Ramakrishnan C, Deisseroth K, Otte S, Stuber GD (2015) Visualizing hypothalamic network dynamics for appetitive and consummatory behaviors. Cell 160:516-527. CrossRef Medline

Johansen JP, Tarpley JW, LeDoux JE, Blair HT (2010) Neural substrates for expectation-modulated fear learning in the amygdala and periaqueductal gray. Nat Neurosci 13:979-986. CrossRef Medline

Kemble ED, Bolwahnn BL (1997) Immediate and long-term effects of novel odors on risk assessment in mice. Physiol Behav 61:543-549. CrossRef Medline

Kim EJ, Horovitz O, Pellman BA, Tan LM, Li Q, Richter-Levin G, Kim JJ (2013) Dorsal periaqueductal gray-amygdala pathway conveys both innate and learned fear responses in rats. Proc Natl Acad Sci U S A 110: 14795-14800. CrossRef Medline

Kincheski GC, Mota-Ortiz SR, Pavesi E, Canteras NS, Carobrez AP (2012) The dorsolateral periaqueductal gray and its role in mediating fear learning to life threatening events. PLoS One 7:e50361. CrossRef Medline

LeDoux J (2012) Rethinking the emotional brain. Neuron 73:653-676. CrossRef Medline

Lin D, Boyle MP, Dollar P, Lee H, Lein ES, Perona P, Anderson DJ (2011) Functional identification of an aggression locus in the mouse hypothalamus. Nature 470:221-226. CrossRef Medline

Lipp HP, Hunsperger RW (1978) Threat, attack and flight elicited by electrical stimulation of the ventromedial hypothalamus of the marmoset monkey Callithrix jacchus. Brain Behav Evol 15:260-293. Medline

Liu D, Gu X, Zhu J, Zhang X, Han Z, Yan W, Cheng Q, Hao J, Fan H, Hou R, Chen Z, Chen Y, Li CT (2014) Medial prefrontal activity during delay 
period contributes to learning of a working memory task. Science 346: 458-463. CrossRef Medline

Malick J (1975) Differential effects of d- and l-amphetamine on mousekilling behavior in rats. Pharmacol Biochem Behav 3:697-699. CrossRef Medline

Martinez RC, Carvalho-Netto EF, Ribeiro-Barbosa ER, Baldo MV, Canteras NS (2011) Amygdalar roles during exposure to a live predator and to a predatorassociated context. Neuroscience 172:314-328. CrossRef Medline

Miguel TT, Nunes-de-Souza RL (2006) Defensive-like behaviors and antinociception induced by NMDA injection into the periaqueductal gray of mice depend on nitric oxide synthesis. Brain Res 1076:42-48. CrossRef Medline

Nashold BS Jr, Wilson WP, Slaughter DG (1969) Sensations evoked by stimulation in the midbrain of man. J Neurosurg 30:14-24. CrossRef Medline

O'Boyle M (1974) Rats and mice together: the predatory nature of the rat's mouse-killing response. Psychol Bull 81:261-269. CrossRef Medline

Papes F, Logan DW, Stowers L (2010) The vomeronasal organ mediates interspecies defensive behaviors through detection of protein pheromone homologs. Cell 141:692-703. CrossRef Medline

Paxinos G, Franklin KBJ (2001) The mouse brain in stereotaxic coordinates. San Diego: Academic.

Petrovich GD, Canteras NS, Swanson LW (2001) Combinatorial amygdalar inputs to hippocampal domains and hypothalamic behavior systems. Brain Res Brain Res Rev 38:247-289. CrossRef Medline
Rylov AL (1985) Changes in predatory and intraspecific aggressiveness of the male rat during food deprivation (in Russian). Zh Vyssh Nerv Deiat Im I P Pavlova 35:875-878. Medline

Schmitzer-Torbert N, Jackson J, Henze D, Harris K, Redish AD (2005) Quantitative measures of cluster quality for use in extracellular recordings. Neuroscience 131:1-11. CrossRef Medline

Silva BA, Mattucci C, Krzywkowski P, Murana E, Illarionova A, Grinevich V, Canteras NS, Ragozzino D, Gross CT (2013) Independent hypothalamic circuits for social and predator fear. Nat Neurosci 16:1731-1733. CrossRef Medline

Stamatakis AM, Stuber GD (2012) Activation of lateral habenula inputs to the ventral midbrain promotes behavioral avoidance. Nat Neurosci 15: 1105-1107. CrossRef Medline

Sukikara MH, Mota-Ortiz SR, Baldo MV, Felicio LF, Canteras NS (2010) The periaqueductal gray and its potential role in maternal behavior inhibition in response to predatory threats. Behav Brain Res 209:226-233. CrossRef Medline

Takahashi LK (1992) Ontogeny of behavioral inhibition induced by unfamiliar adult male conspecifics in preweanling rats. Physiol Behav 52:493498. CrossRef Medline

Wang L, Chen IZ, Lin D (2015) Collateral pathways from the ventromedial hypothalamus mediate defensive behaviors. Neuron 85:1344-1358. CrossRef Medline 